\title{
Demonstration of Hyperspectral Image Exploitation for Military Applications
}

\author{
Jean-Pierre Ardouin ${ }^{1}$, Josée Lévesque ${ }^{1}$, \\ Vincent Roy ${ }^{1}$, Yves Van Chestein ${ }^{1}$ and Anthony Faust ${ }^{2}$ \\ ${ }^{1}$ Defence RED Canada, Valcartier \\ ${ }^{2}$ Defence RED Canada, Suffield \\ Canada
}

\section{Introduction}

Airborne hyperspectral imagers have been available from various providers for many years and their performance keeps improving. On the other hand, space-based hyperspectral sensors have only been available from few exploratory missions such as NASA Hyperion on EO-1 (Pearlman et al, 2003) and ESA CHRIS on Proba (Cutter et al, 2003). In recent years, there have been many civilian space missions being planned in different countries (Buckingham \& Staenz, 2008), as well as military space demonstrations (Cooley et al, 2006).

Given the increase in potential space-based hyperspectral sensors, Defence R\&D Canada (DRDC), which is part of the Canadian department of National defence, began in 2005 a project to demonstrate the military utility of space-based reflective hyperspectral imagery (0.4-2.5 microns) to the Canadian Forces (CF). The project is called HYperspectral iMage EXploitation (HYMEX) and ended its activities in 2010 (Ardouin et al, 2007).

Before the HYMEX project, DRDC had been conducting and sponsoring R\&D in the area of hyperspectral image exploitation for a number of years to explore its various possibilities (Davenport \& Ressl, 1999; Sentlinger et al, 2003; Webster et al, 2006). The focus of this work was on military target detection applications. In parallel with these activities, the Canadian remote sensing community has also been active in developing hyperspectral applications for various civilian applications related to forestry, agriculture, fisheries, mineral exploration and environmental monitoring (Buckingham et al, 2002). Many hyperspectral techniques developed for civilian applications can be applied to military applications such as terrain characterization.

Building on previous efforts at DRDC and with support from Canadian industry, academic institutions and other government departments, the HYMEX project identified a set of applications and related algorithms to be demonstrated to the Canadian Forces.

This chapter presents an overview of the project, beginning with a description of its main activities (Section 2.0), including field trials, data analysis and algorithms evaluation and the development of an image exploitation software. Then, for each application areas, target detection (Section 3.0), land mapping (Section 4.0) and marine mapping (Section 5.0), we 
discuss some of the most promising algorithms and show examples of application of these algorithms.

\section{HYMEX applications and activities}

The HYMEX project addressed applications divided in 3 categories:

1. Target detection and identification: This includes targets such as military vehicles, camouflages and various man-made materials.

2. Land mapping applications: This includes the characterization of soil and vegetation.

3. Marine mapping applications: This includes beach characterization and near-shore bathymetry, as well as water color mapping.

As mentioned in the introduction, DRDC developed expertise and advanced exploitation techniques for target detection over the years but had limited expertise for terrain analysis and water mapping. To identify available techniques for the last 2 categories, HYMEX conducted a survey of about 60 different groups from industry, academia and other government departments forming the Canadian remote sensing community. Most algorithms from the groups that responded have been included in the project.

The project delivered a suite of near-operational hyperspectral image exploitation tools called HOST (Hyperspectral Operational Support Tools). HOST is developed in the IDL language as an add-on to a commercial-off-the-shelf package called ENVI available from ITT Visual Information Solutions. ENVI is already a widely used platform for hyperspectral image analysis. HOST builds onto ENVI to provide tools specifically oriented for the needs of the Canadian Forces. The HYMEX System Integrator responsible for the development of HOST was MacDonald Dettwiler and Associates (Richmond, BC).

HYMEX adopted an algorithms validation strategy that led to the selection of the best algorithms to be integrated into HOST and explore the performance limits of these algorithms. Knowing these limits is an important element of information for transitioning the tools into operational use by the Canadian Forces. The validation strategy included the following components:

Field Trials: The HYMEX project conducted several field trials at different locations across Canada to acquire remotely sensed hyperspectral imagery and ground truth for testing the various algorithms. Each location had specific characteristics likely to affect the performance of the algorithms. Marine trials were conducted in two different locations (East and West coast). Land trials were conducted in an Acadian forest (CFB Gagetown, NB), a boreal forest (CFB Valcartier, QC), an aspen dominant forest (CFB Wainwright, $A B$ ) and in prairie grassland (CFB Suffield, $A B)$. One trial was conducted in winter under snow conditions. While some space-based hyperspectral imagery was acquired, the project main data type came from airborne hyperspectral sensors. Airborne data contains similar information as space-based sensors, and can be used in the interim to evaluate algorithms. In fact, even though HYMEX focused on demonstrating the utility of space-based imagery, the results can easily be transposed into the utility of airborne sensors.

Data analysis: All HYMEX algorithm providers analyzed trial data using performance metrics approved by DRDC. In addition to providing quantitative performance evaluation and comparisons of the algorithms, the overall data analysis allowed the demonstration in a 
limited way of a) how the performance varies in different environments, b) the advantage of hyperspectral (HSI) over multispectral (MSI) imagery and c) the effect of varying ground sampling distance (GSD) via the analysis of airborne data at different altitudes or of different sensors.
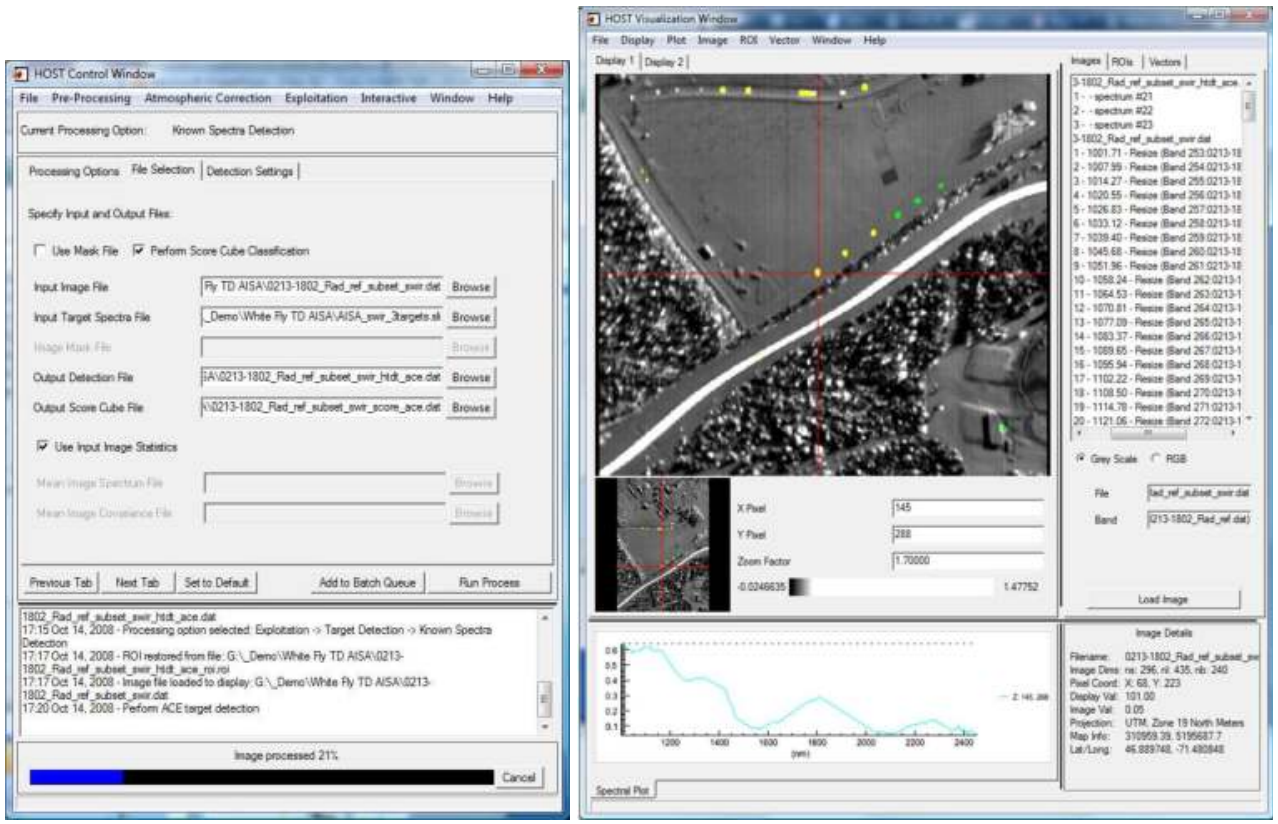

Fig. 1. HOST two main windows: the visualization window on the left and the control window on the right

HOST demonstrations: We developed the HOST software in three successive iterations. Each iteration ended with a live or hands-on demonstration of the tools to CF stakeholders and image analysts. Feedback from the demonstration participants were integrated in the following iterations and the selection of the algorithms to be integrated for the iteration was based on interim data analysis results. As explained above, HOST is an add-on to ENVI. While ENVI is a powerful exploitation package for advanced hyperspectral imagery users, HOST is oriented towards military end-users with introductory knowledge of hyperspectral image exploitation. In order to present a simplified and more uniform user interface than ENVI, HOST is organized in two main windows as illustrated in Figure 1: the visualization window and the control window. The HOST visualization window regroups, in a single window, many of the familiar visualization tools offered by ENVI (image display, plot display, available bands list, region of interest tool and the vector layer manipulation tool). By regrouping these tools in a single window, the user can more easily keep track of these functions as they are applied to specific hyperspectral images. The control window provides, in a single window, an interface to the parameters of the different advanced exploitation algorithms offered by HOST. The user would typically use the control window to setup batch scripts to process many hyperspectral images without user intervention. The HOST control window is organized in different logical categories of algorithms such as: pre- 
processing, atmospheric correction, exploitation and interactive tools. A Navigation Tool also allows loading customized task descriptions with links to the HOST user interface. This guides the user through the algorithms needed to accomplish a task and the selection of the parameters for those algorithms.

\section{Target detection algorithms}

Throughout the HYMEX project, DRDC gained experience in applying algorithms for target detection applications. In this section, we describe a typical processing chain (atmospheric correction, detection and target abundance estimation (Roy, 2010)) used in the project and present results from an experiment aimed at evaluating the performance of the target abundance estimation part of the processing chain using data collected in difficult illumination and atmospheric conditions.

In late October and early November 2009, DRDC collected airborne hyperspectral imagery near Suffield, Alberta $\left(50^{\circ} 13^{\prime} \mathrm{N}, 110^{\circ} 10^{\prime} \mathrm{W}\right)$ using an Itres SASI-600 SWIR pushbroom imaging system. The sensor was flown at various altitudes ranging from $330 \mathrm{~m}$ to $1700 \mathrm{~m}$ above ground level in order to acquire imagery at across-track ground sampling distance (GSD) of $0.4 \mathrm{~m}, 1.0 \mathrm{~m}$, and $2.0 \mathrm{~m}$, while along-track GSD remained constant at $1.0 \mathrm{~m}$. Imagery was collected between $13 \mathrm{~h} 00$ and $15 \mathrm{~h} 00$ local time, which resulted in sun elevation between 17 and 25 degrees. Furthermore, thin altostratus clouds and an overcast of altocumulus clouds on the first $(29$ Oct) and second day (03 Nov) of collect respectively degraded the illumination conditions considerably, as illustrated in Figure 2. Compared to typical reflective hyperspectral field trials usually conducted under clear skies and high solar elevation, this data collection was conducted under significantly adverse environmental conditions not often considered in the hyperspectral literature.
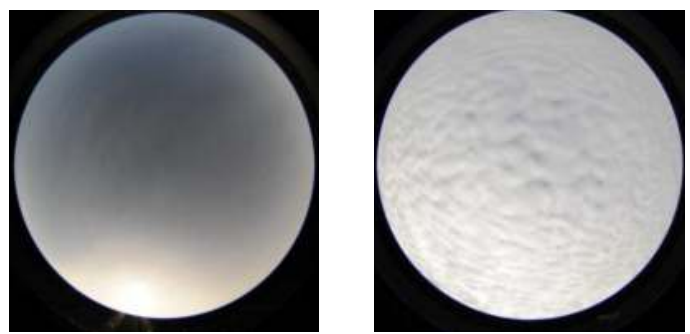

Fig. 2. Typical sky conditions on 29 Oct 2009 (left) and 03 Nov 2009 (right).

One objective of this field trial was the evaluation of the constrained energy minimisation (CEM) algorithm (Settle, 2002) sub-pixel abundance estimation accuracy. For this purpose, we designed targets of known abundances made of thin strips of painted metal, as illustrated in Figure 3 below. The design allowed changes to the abundance level by varying the distance between the strips of metals while their overall size $(5 \mathrm{~m} \times 5 \mathrm{~m})$ ensured that they filled completely at least one pixel in the imagery, as showed in Figure 4. We used two different types of paint to vary the contrast between the target and background, one beige (see Figure 3) and one green (not shown). The base color was mixed with small quantities (2 to $10 \%$ per volume) of black feature-less paint to control the spectral features depth and overall signature albedo. A total of 6 targets were used in this experiment. 

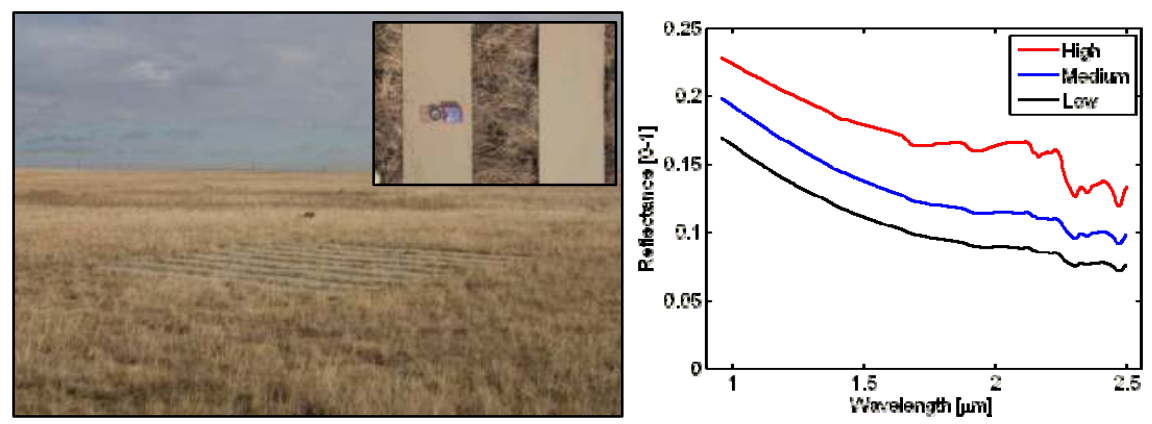

Fig. 3. Left) Example of controlled abundance target. Right) Spectral signatures of the beige paint at different albedo levels, as measured in field conditions using an ASD FieldSpec Pro spectrometer.
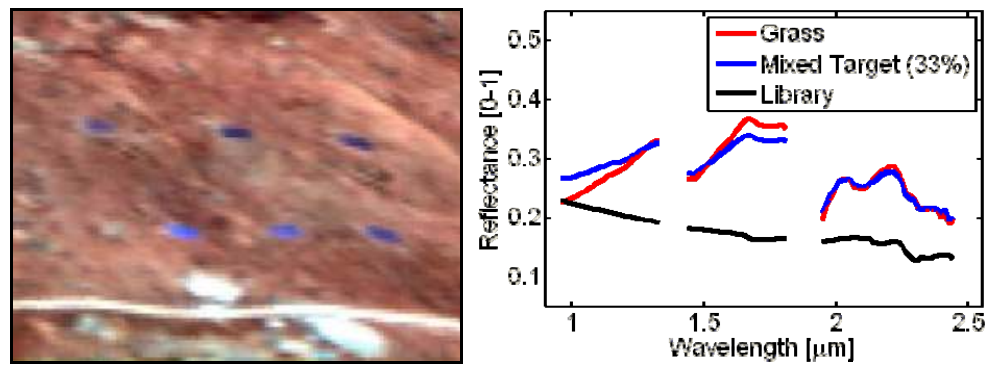

Fig. 4. Left) SWIR 3-colors composite of targets, imaged at a 2.4m GSD (coarsest resolution). Right) Background (red) and target (blue) signatures as measured by the airborne sensor, compared to the target library signature (black).

DRDC favours automated and adaptive approaches to hyperspectral target detection, minimizing user interaction and processing time as much as possible. In this context, we used the following processing chain for this dataset exploitation:

1. We first manually identified and removed 12 out of the original 100 spectral bands due to their low signal to noise level. We also removed unusable part of the imagery due to sensor vignetting. This is typically done only once for a given sensor.

2. We then converted the imagery from at-aperture radiance to apparent reflectance units using the empirical line method (Smith \& Milton, 1999), with five very large targets (greater than 10x10 pixels) of known reflectance. This was possible due to the controlled environment of this imagery collection; else we would typically have used a semiempirical technique such as the QUick Atmospheric Correction (QUAC) method (Bernstein et al, 2005).

3. The CEM algorithm requires a description of the background $2^{\text {nd }}$ order statistics (mean and covariance). For this calculation, we identified a subset of background pixels from the complete image using the RX anomaly detection algorithm (Reed \& Yu, 1990) by keeping only the first $90 \%$ lowest scoring pixels. Second order statistics were then evaluated using this limited set of pixels. 
4. Finally, we calculated the score for all pixels of the image using the CEM algorithm. As described in Settle (2002), when properly normalised, the CEM output is an estimation of the searched target signature abundance in the pixel under test.

The controlled ground targets were collected in 45 different images. On 29 Oct, the abundance was set to $50 \%$ while on 03 Nov it was reduced to $33 \%$. All images were manually interpreted to delineate the area of the targets in the images. The CEM scores were averaged over each target area to derive an "average abundance", as shown in Figure 5. This was necessary because as imaged, the targets had inhomogeneous abundance over their physical extent, particularly at the finest GSDs. This suggests that the target design could be improved for future experiments by using thinner strips of material more closely spaced together.
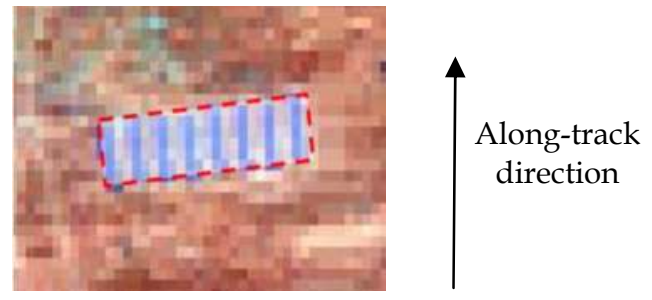

Fig. 5. Example of manual delineation of target area. Target is $5 \mathrm{~m} \times 5 \mathrm{~m}$, GSD is $0.4 \mathrm{~m}$ (acrosstrack) by $1.0 \mathrm{~m}$ (along track).

Estimated abundance error was calculated using the root mean square error (RMSE) and the estimation bias, both normalized by the true abundance in order to get a relative error in percent:

$$
\begin{gathered}
\text { Relative RMSE [\%] }=\frac{100 \%}{\alpha_{\text {true }}} * \sqrt{\frac{\sum\left(\alpha_{\text {evaluated }}-\alpha_{\text {true }}\right)^{2}}{N}} \\
\text { Relative bias }=\frac{100 \%}{\alpha_{\text {true }}} * \frac{1}{N} \sum\left(\alpha_{\text {evaluated }}-\alpha_{\text {true }}\right)
\end{gathered}
$$

RMSE results are presented in Table 1. Overall, the root mean square error for this experiment is between $11.7 \%$ and $30 \%$. In absolute terms, the overall RMSE translates to 0.064 and 0.078 for the 0.5 and 0.33 abundance targets respectively. The retrieved abundances were slightly underestimated, with bias of $-1.9 \%$ and $-14.7 \%$ again on the 0.5 and 0.33 abundance targets respectively. Since atmospheric conditions degraded between the two collects, it is unclear if the observed increase in error is related to the change in illumination conditions, to the lower abundance level considered, or to a combination of both.

The results achieved are encouraging and show that target abundance can be retrieved at the subpixel level using the CEM algorithm with a high accuracy. The fact that the estimated abundances are generally lower than the true abundances which is consistent with an error that could have been introduced during the manual delineation of targets area, by assigning larger areas to targets than their true area. Also, the imaging system true point spread function has not been characterized and taken into account in this analysis; non-uniform sampling over the GSD could lead to an underestimation of the sub-pixel abundances (Settle, 2004). 


\begin{tabular}{|c|c||c|c||}
\hline \multicolumn{2}{|c||}{ Target type } & \multicolumn{2}{c|}{ Target configuration } \\
\hline Contrast type & Albedo type & $\alpha=0.5$ (29 Oct 2009) & $\alpha=0.33$ (03 Nov 2009) \\
\hline \hline High (beige) & High & 11.7 & 30.0 \\
\hline High (beige) & Medium & 13.4 & 24.3 \\
\hline High (beige) & Low & 12.8 & 19.6 \\
\hline Low (green) & High & 11.9 & 20.8 \\
\hline Low (green) & Medium & 13.2 & 24.5 \\
\hline Low (green) & Low & 13.2 & 21.7 \\
\hline \multicolumn{2}{|c|}{ Average over all targets: } & 12.7 & 23.5 \\
\hline
\end{tabular}

Table 1. Relative RMS errors of the retrieved abundances using the CEM algorithm; $\alpha$ denotes the target abundance.

The results demonstrate the robustness of the processing chain; with minimal user interaction and using a simple processing chain suitable for near real-time exploitation, targets can be characterized at the sub-pixel level even under adverse illumination conditions. This demonstrates the processing chain's military utility, and indicates that it could be adapted to the detection and characterization of spectral signatures of interest in a military operational context.

\section{Land mapping applications}

Land mapping applications were studied in collaboration with the University of NewBrunswick, the University of Alberta, the University of Lethbridge, York University and Laval University. The work was oriented towards soil and vegetation characterization and mapping for trafficability and environmental applications. In Section 4.1, algorithms for classification and the extraction of vegetation canopy attributes (density, structure) were evaluated using airborne hyperspectral data acquired over three Canadian Forces bases (CFB). The resulting validated hyperspectral products were then used to improve a trafficability model developed by the University of New Brunswick for Gagetown military base as well as promote environmentally sustainable training on military bases. Winter airborne images were also acquired over the Montmorency experimental forest (near Quebec City) to investigate the potential of winter imagery to better derive forest information. In Section 4.2 we show that among the classification algorithms that were evaluated, the Mercury algorithm (an evidential-reasoning-based supervised classification algorithm developed by the University of Lethbridge (Peddle \& Ferguson, 2002)) achieved the best performance. Finally, Section 4.3 shows results from a laboratory study conducted by the University of Alberta demonstrating how hyperspectral techniques can be used to discriminate between vegetation stresses caused by exposure to different toxic industrial chemicals (Rogge et al, 2008).

\subsection{Trafficability and the monitoring of military training areas}

This section presents results obtained for the two main land applications of HYMEX, trafficability and the monitoring of training ranges to promote environmentally sustainable 
training. Table 2 provides a summary of the trials and the objectives sought for each application. The primary objective of each trial was the validation of algorithms used to derive vegetation cover information such as type, density and height, the presence of wetlands and the determination of soil type. These surface features are easily derived from hyperspectral imagery and can contribute to improve knowledge of the terrain for the purposes of trafficability and environmental applications. Each trial was conducted in a different vegetation background ranging from various forest biomes (deciduous, mixte, boreal) to prairie grassland. Details regarding each trial, the available ground truth and the algorithms used to analyse the various datasets can be found in (Ardouin et al, 2007).

\begin{tabular}{|c|c|c|c|c|c|c|}
\hline Trial location & Date & Sensor & GSD & Background & Objectives & Application \\
\hline $\begin{array}{l}\text { CFB Gagetown, } \\
\text { NB }\end{array}$ & Sep 2005 & Probe-1 & $15 \mathrm{~m}$ & Acadian forest & $\begin{array}{l}\text { Forest parameter } \\
\text { algorithms validation } \\
\text { (mixed deciduous) \& } \\
\text { CFB Gagetown } \\
\text { trafficability model }\end{array}$ & $\begin{array}{l}\text { trafficability \& } \\
\text { sustainable } \\
\text { training }\end{array}$ \\
\hline $\begin{array}{l}\text { CFB } \\
\text { Wainwright, } \mathrm{AB}\end{array}$ & Sep 2006 & AISA & $4 \mathrm{~m}$ & Boreal/grassland & $\begin{array}{l}\text { Forest parameter } \\
\text { algorithms validation } \\
\text { (single deciduous } \\
\text { species) }\end{array}$ & trafficability \\
\hline $\begin{array}{l}\text { Montmorency } \\
\text { Experimental } \\
\text { Forest, QC }\end{array}$ & $\begin{array}{l}\text { Jun } 2004 \\
\text { Feb } 2007\end{array}$ & AISA & $\begin{array}{l}4 \mathrm{~m} \\
4 \mathrm{~m}\end{array}$ & $\begin{array}{l}\text { Boreal/summer } \\
\text { Boreal/winter }\end{array}$ & $\begin{array}{l}\text { Forest parameter } \\
\text { algorithms validation } \\
\text { (mixed conifers), } \\
\text { wetland mapping \& } \\
\text { summer/winter } \\
\text { dataset investigation }\end{array}$ & trafficability \\
\hline CFB Suffield, AB & Sep 2006 & AISA & $4 \mathrm{~m}$ & Prairie grassland & $\begin{array}{l}\text { Map invasive species, } \\
\text { burnt areas, soil } \\
\text { disturbance }\end{array}$ & $\begin{array}{l}\text { sustainable } \\
\text { training }\end{array}$ \\
\hline
\end{tabular}

Table 2. HYMEX land mapping application trials

CFB Gagetown trial. One of the objectives of this trial was to improve the trafficability model used by the Army Meteorological Center (AMC) at CFB Gagetown to plan training exercises, avoid erosion by vehicles and promote environmentally sustainable training. The model currently use as input, the soil moisture content simulated by the University of New Brunswick (UNB) Forest Hydrology Model (ForHyM2) which is based on air and ground temperatures, soil type, the amount of precipitation and the wind speed and direction. Improvement of the trafficability model was achieved by the addition of above ground restrictions such as the forest type (hard/softwood), density and height which can be readily derived from hyperspectral remote sensing. Figure $6 \mathrm{~b}$ shows a vegetation species classification derived from 15m GSD imagery collected by the Probe-1 sensor (Figure 6a). The overall accuracy (81.8\%) and Kappa coefficient (0.78) are based on 533 pixels. These results were obtained with the University of Lethbridge Mercury classification algorithm. Figure 7 shows the shadow fraction of the forest canopy which was derived from spectral mixture analysis (SMA) (Peddle \& Smith, 2005) along with the sunlit deciduous fraction, the sunlit conifer fraction and the background fraction. The image shadow fraction was found to correlate the best with LAI, as measured on the ground on 29 plots with hemispherical 
pictures $\left(R^{2}=0.55\right)$ with an average difference between the SMA LAI and the ground LAI of less than 0.5 LAI. Figures $8 \mathrm{a}$ and $8 \mathrm{~b}$ show two forest canopy structures, stem density and stand height, as output from the University of Lethbridge Multiple Forward Mode 3-D Canopy Reflectance Model (MFM-3D) applied to the modified geometric optical mutual shadowing model (GOMS) (Peddle et al, 2003). MFM-3D uses a Look-up-tables (LUT) approach based on various ranges and increments of forest structure parameters (density, horizontal \& vertical crown radius, crown height and height distribution) as input. The ranges and increments can be determined either from field data or automatically without prior knowledge. Inversion of MFM-3D model produces results when image reflectance values match the modelled reflectance. Field and MFM-3D stand height produced less than $2 \mathrm{~m}$ average height difference with the under-estimation of the MFM-3D model attributed to the difficulty in locating neighbouring pixels with similarity to the center pixel.

The addition of above ground restrictions to UNB trafficability model, as determined by the vegetation layers described above, helps produce more refined trafficability classes as illustrated in Figure 9. Figure 10a shows the graphical user interface (GUI) of the route planning tool. Once all the available layers are loaded into the Input Dialog, the user can select from the Interactive Parameters which restrictions to apply for a particular vehicle type. Examples of route planning for four types of military vehicles are shown in Figure 10b with a low environmental concern (not avoiding areas with a high rutting index), and 10c with a high environmental concern (avoiding areas prone to produce ruts).

(a)

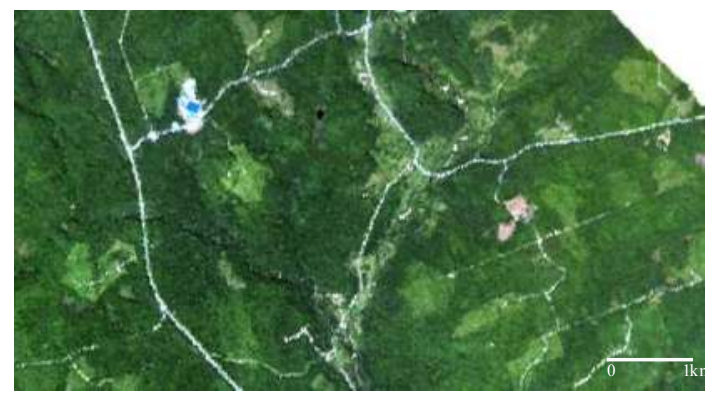

$R: 672 n m, G: 549 n m, B: 488 n m$

(b)

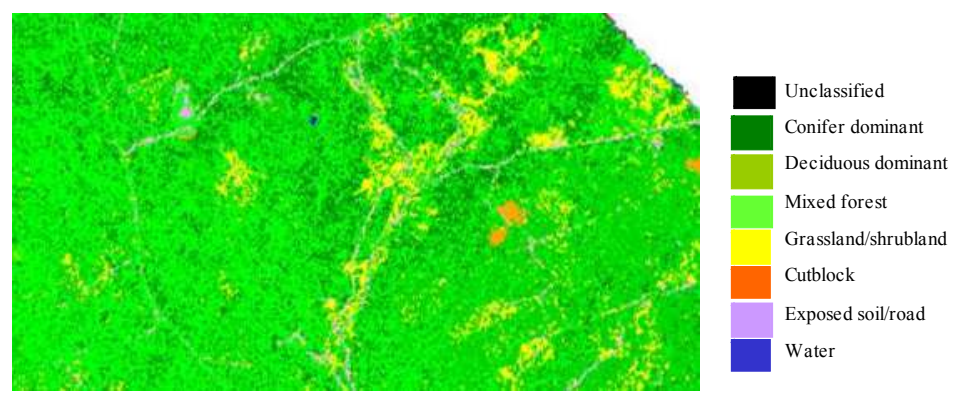

Fig. 6. (a) Sub-image of Probe-1 airborne imagery of CFB Gagetown and (b) landcover classification derived from an evidential reasoning classifier with classes of vegetation and exposed soil and roads. Overall accuracy: 81.8\%. Kappa coefficient: 0.78 (D. Peddle, U. of Lethbridge). 


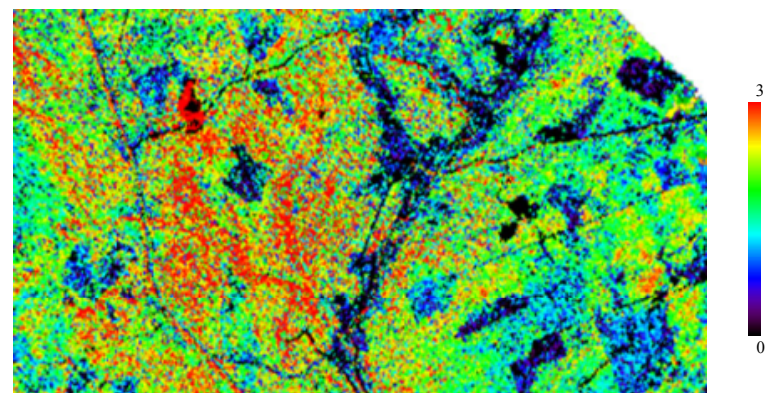

Fig. 7. Sub-image of Probe-1 airborne imagery of CFB Gagetown showing the shadow fraction of the forest canopy derived from spectral mixture analysis (D. Peddle, U. of Lethbridge).

a)

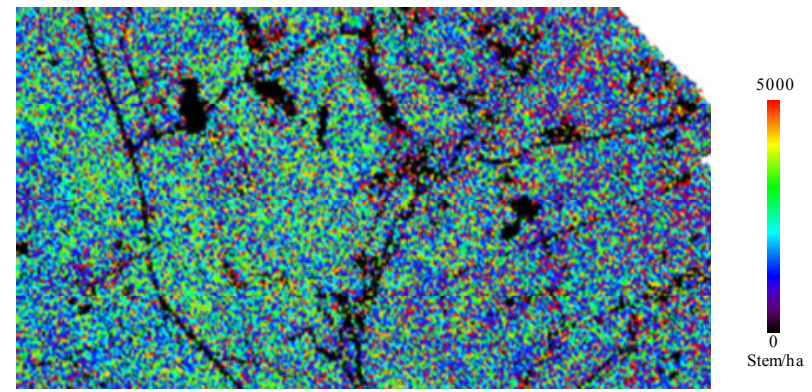

(b)

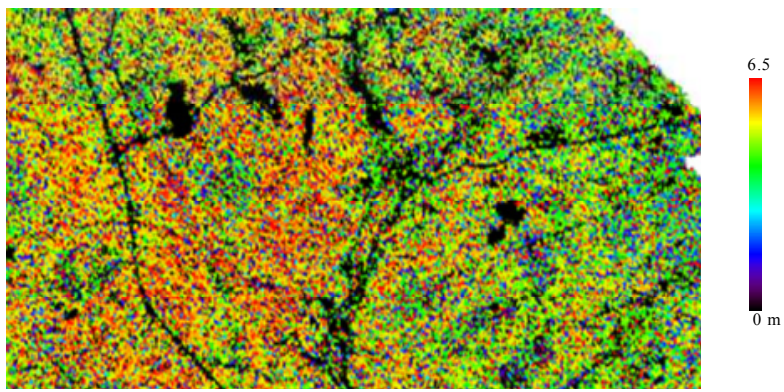

Fig. 8. Sub-image of Probe-1 airborne imagery of CFB Gagetown showing forest structural parameters (a) stand density and (b) stand height as derived from the MFM-3D model (D. Peddle, U. of Lethbridge). 

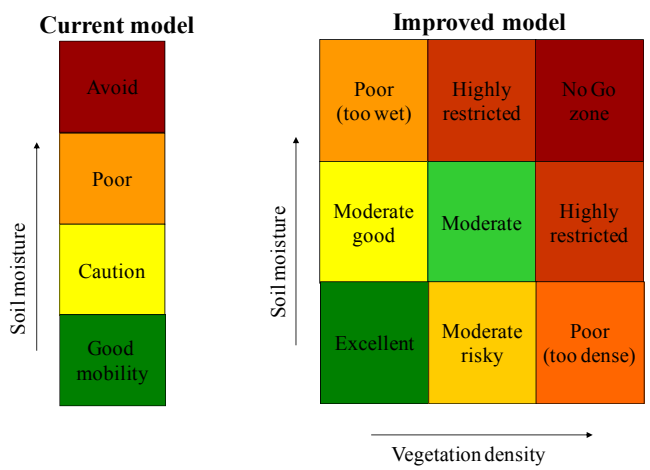

Fig. 9. Off-road trafficability classes for the current (left) and improved models (right).

(a)

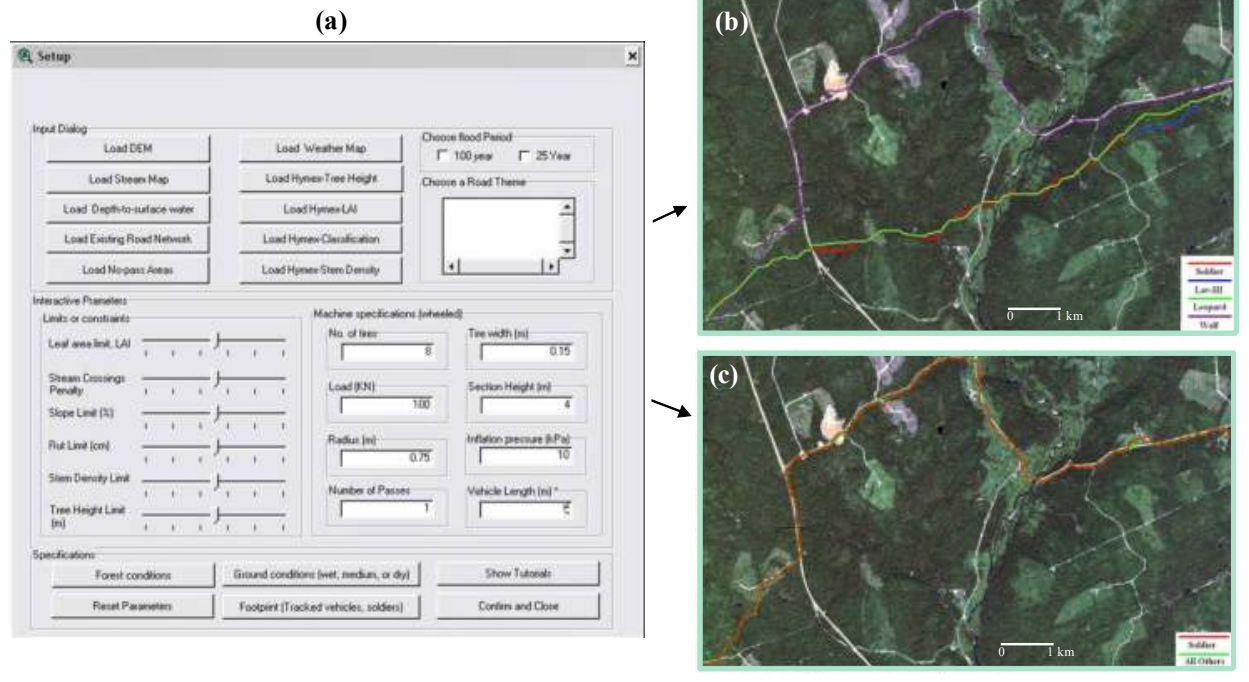

Fig. 10. (a) Route planning for four military vehicles with (b) low and (c) high environmental concern.

CFB Wainwright trial. A similar trafficability model was also constructed by UNB for CFB Wainwright with the objective to demonstrate its portability to different soil and vegetation ecosystems. The above ground trafficability is determined by a semi-arid prairie landscape with well defined dry and wet seasons. The vegetation is composed of grassland with areas of deciduous trees (aspen, balsam poplar and willow) and the topography is gentle. The hyperspectral vegetation products made available to UNB are the land cover classes and the leaf area index (LAI) (Figures $11 \mathrm{~b}$ and 11c) provided by York University under contract to HYMEX. Figures $11 \mathrm{~d}$ to $11 \mathrm{f}$ show the optimal route planning between point $A$ and point $B$ using a Wolf and a LAV vehicles when constrained by wet areas and vegetation during the wet season (Figure 11d), when constrained by wet areas and vegetation during the dry season (Figure 11e) and when constrained by wet areas and vegetation during the wet season and the requirement to move along tree lines as closely as possible (Figure 11f). 


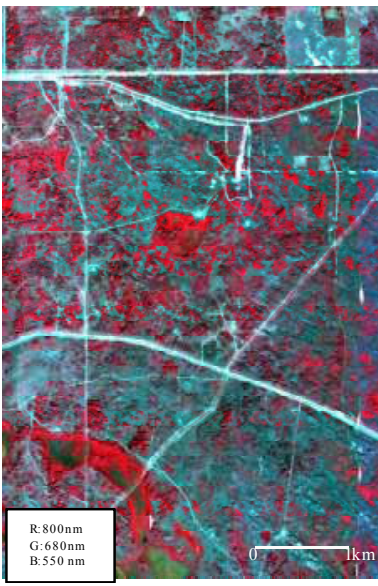

(a)

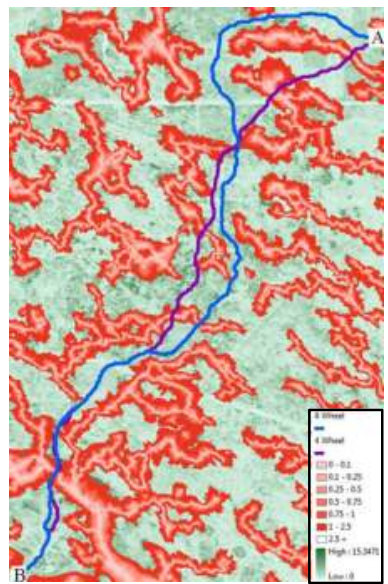

(d)

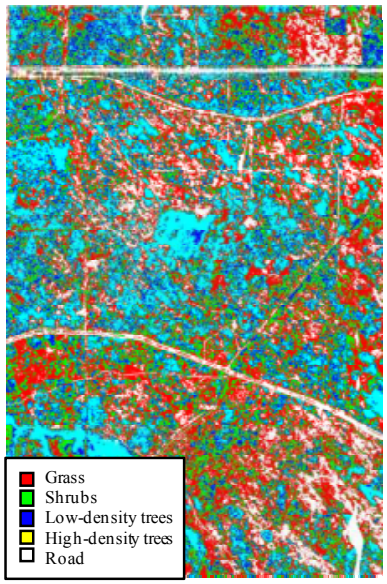

(b)

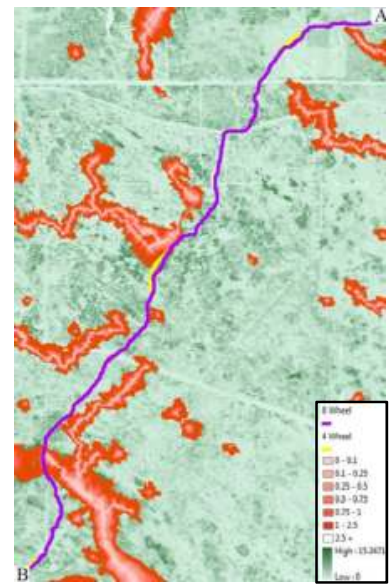

(e)

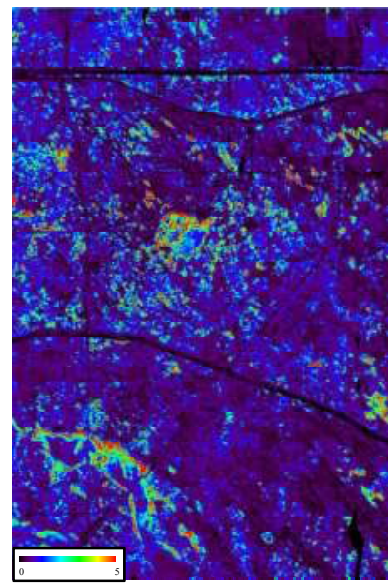

(c)

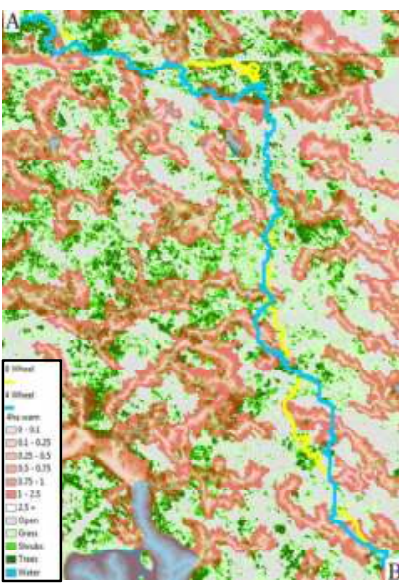

(f)

Fig. 11. (a) AISA color composite, (b) land cover classes and (c) leaf area index map of CFB Wainwright (York University). Route between A and B for a Wolf and a LAV vehicles: (d) when constrained by wet season conditions, (e) when constrained by dry season conditions and (f) when constrained by wet season conditions and the requirement to move along tree lines (UNB).

Montmorency Experiment Forest (MEF) trials. Two airborne hyperspectral datasets are available for the MEF site, one from Jun 2004 (summer) and one from Feb 2007 (winter). The objective for imaging this site was to test algorithms for vegetation mapping in a coniferous dominant forest ecosystem. The winter 2007 dataset was acquired for the purpose of investigating the usefulness of summer/winter data to extract relevant terrain information for trafficability in the boreal forest. One first attempt to address this later objective is to map tamarack trees (Larix laricina) which can be used as an indicator species for the location of peatlands areas dominated by trees, a wetland type being of interest for trafficability. 
Tamarack trees thrive in open areas because of their intolerance to shade and their resentment to compete with other species (Beeftink, 1951). They also adapt very well to poorly drained soil. Their presence is generally associated with peatlands although their absence do not indicate that there is no wetlands. Spectrally, tamaracks are similar to other conifers in summer and to deciduous trees in winter because they loose their leaves (needles) before winter. A combination of summer and winter data allows the exploitation of this unique characteristic of the tamarack trees to locate and map treed wetlands. Figure $12 \mathrm{~b}$ shows a RGB of AISA data acquired in winter 2007 at the MEF. Figure 12c is a moisture stress vegetation index in which the red color represents exposed bark. When looking closer at the single tree where the red arrow is pointing in Figure 12a, it is easy to recognise from the shape of its shadow on the snow that it is a defoliated coniferous tree. Not having this information on hand it would be difficult to determine whether the trees in the red color class in Figure 12c are deciduous, dead spruce or fir, or dormant tamarack.

Under contract to DRDC, Laval University applied four filters, each made of a band ratio index and a predefined threshold, to classify the tamarack trees in the AISA image with 95\% of the tamarack pixels correctly classified and only $1.2 \%$ of the remaining pixels misclassified as hardwood trees. Each filter discriminates tamarack trees from other forest features such as other softwood and deciduous. The effects of the application of the first 3 and the first 4 filters are shown in Figure 13a and 13b.

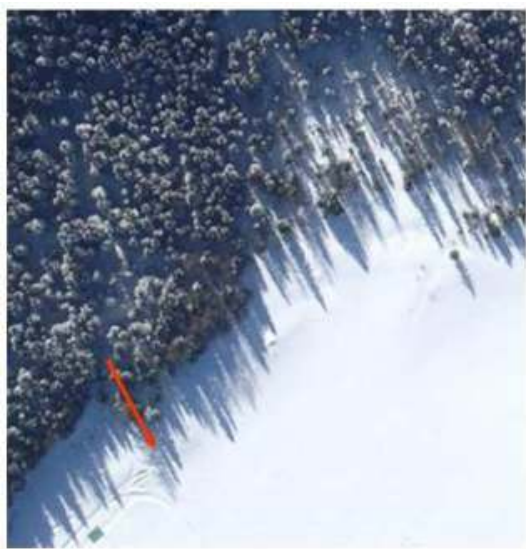

(a)

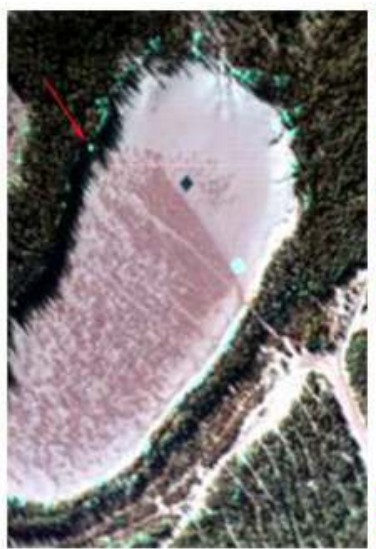

(b)

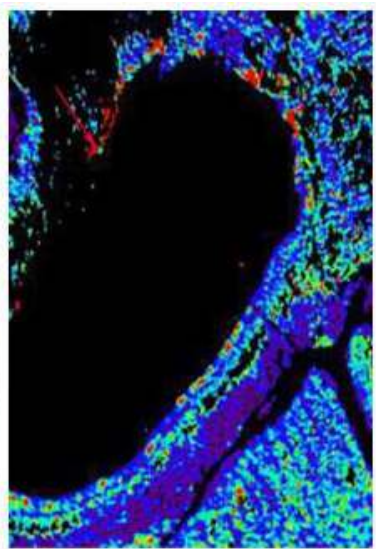

(c)

Fig. 12. (a) high resolution color image, (b) AISA color composite (R:1290 nm , G:1655 nm, B:2189 nm), and (c) a moisture stress vegetation index from the AISA winter image of an area at the Montmorency experimental forest. The red arrow points at a tamarack tree.

CFB Suffield trial. The objectives of this trial were primarily environmentally oriented. Despite a semi-arid climate, prairie grasslands are very sensitive to the introduction of invasive species which are often dispersed during military training and along the maintenance roads of pipelines and gas wells. Leafy spurge and crested wheat are the main invasive species and can easily spread in windward direction into preserved native prairie areas. Moreover, there is a need for monitoring training areas for an environmentally sustainable training. This is to ensure that excessive training does not over stress the soil and 


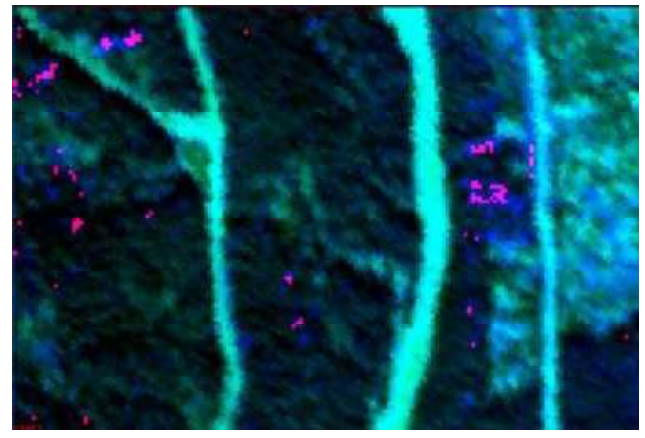

(a)

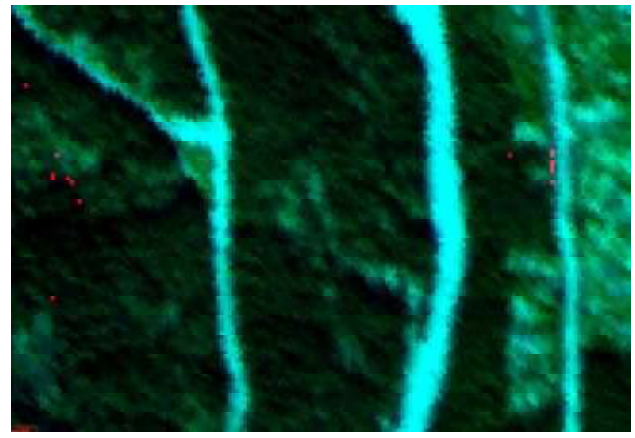

(b)

Fig. 13. (a) result from applying the first 3 filters in which several hardwood pixels are misclassified as tamarack, and (b) result from applying the first 4 filters (red dots are correctly classified tamarack pixels). (Prof. Sylvie Daniel and Gaël Briant, Laval University).

therefore the vegetation capacity to recover. The imaged areas include a wide range of soil and vegetation species including invasive species, burned areas, cultivation and grazing areas, wetlands, and various levels of disturbances by vehicle pathways. At the time of the airborne hyperspectral survey (Sep 2006), the prairie landscape was dry and with the exception of the low lands and around wetlands, the vegetation exhibited a low photosynthetic activity which resulted in less pigment absorption in the visible and more apparent absorption features in the short wave infrared by other plant cell constituents such as lignin and cellulose. The following results obtained by the University of Alberta (under contract for HYMEX) demonstrate the potential of this dataset for mapping soil and vegetation at CFB Suffield to help the environmentally sound planning of military exercises.

Soil was determined to have a high clay content. Thus, exposed soil was mapped using the spatial distribution of the depth of the clay absorption feature in the vicinity of $2200 \mathrm{~nm}$ after removing the vegetation effect using an orthogonal subspace projection and known green and dry vegetation endmember spectra (Figure 14b). Band depth was measured using the continuum removal between $2210 \mathrm{~nm}$ and $2230 \mathrm{~nm}$. The band depth was classified into four classes (Figure 14c) defined as (1) low clay absorption depth (green) corresponding to natural undisturbed terrain, (2) slightly (yellow) and strongly (blue) disturbed soils areas and (4) high clay absorption (red) which correspond to bare soils, active roads, non-vegetated dry wetlands and burnt areas. In undisturbed grassland areas the soil is covered with dry grass, old grass residue and a layer of moss. When the surface is disturbed, some of the soil becomes exposed and the amount of moss and old residues decreases. Thus, a good indicator of vegetation recovery following exercises would be a dominance of dry grass. Figure 14d shows an RGB of the clay band depth (red), the most dominant grass endmember (green) and an endmember associated with spectra of moss covered soil measured with a field spectrometer (blue). These three classes of endmembers can easily be associated with the following three conditions: (1) permanently disturbed areas such as roads and areas surrounding gas wells (red), (2) recently disturbed areas where the moss and old residues are removed (green) and (3) undisturbed areas covered by moss, old residues and grass (blue).

Invasive species could not be spectrally identified due to the overall dryness of the vegetation cover. The RGB composite of Figure 15b displays the most abundant green 


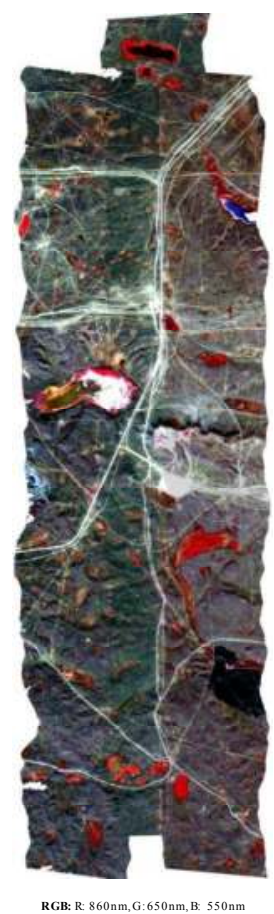

(a)

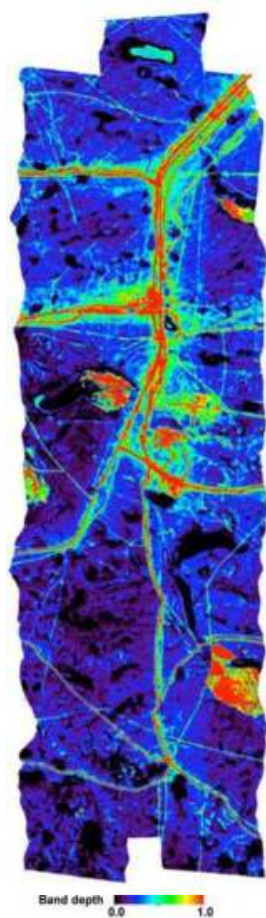

(b)

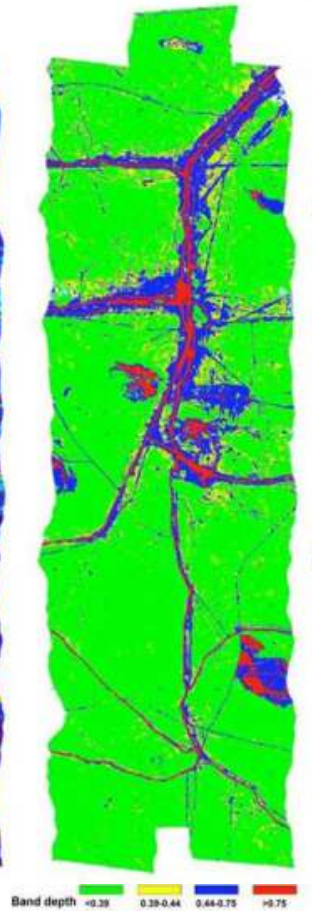

(c)

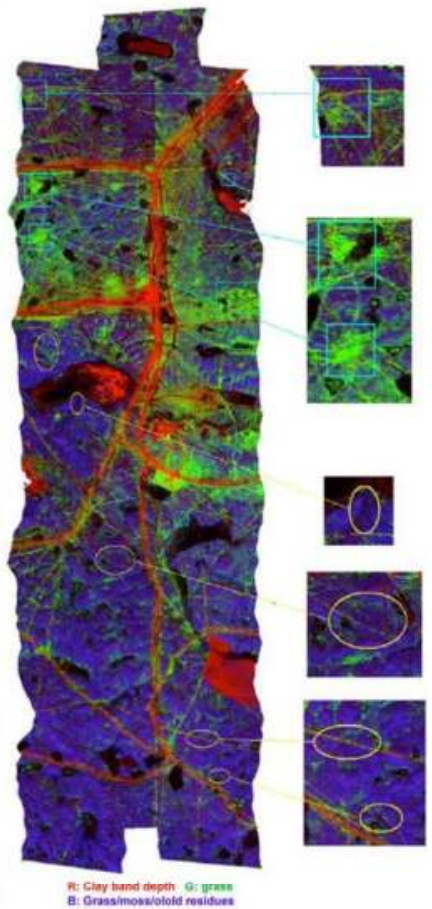

(d)

Fig. 14. (a) AISA imagery RGB color composite, (b) soil clay band depth, (c) classification of soil clay band depth and (d) RGB of the clay band depth (red), the most dominant grass endmember (green) and moss covered soil spectra (blue). (B. Rivard, U. of Alberta)

vegetation endmember in red and the two dominant dry vegetation endmembers in green and blue. The green vegetation (Red color) is located in low land areas which are often located in the vicinity of wetlands. Local cattle grazing is allowed in some area of the military base. The dry vegetation shown in blue represents overgrazed areas which can be compared to impacted areas from training exercise in other area of the military base, thus showing the potential for environmental monitoring for sustainable training. The black area in the northern part represents a recently burnt area where vegetation hasn't started to grow back.

\subsection{Classification algorithms comparison}

As indicated in the previous section, the Mercury supervised classification algorithm (Peddle \& Ferguson, 2002) performed well during HYMEX field trials and as a result was integrated into the HOST software. In order to evaluate its performance in more details, we compared Mercury to all the supervised classification algorithms offered by the ITT's ENVI 4.8 software (Van Chestein, 2011). Two data sets were used, a $15 \mathrm{~m}$ spatial resolution Probe1 hyperspectral image of CFB Gagetown and a $4 \mathrm{~m}$ resolution AISA hyperspectral imagery of CFB Wainwright. The classes defined for each dataset are listed in Table 3. 


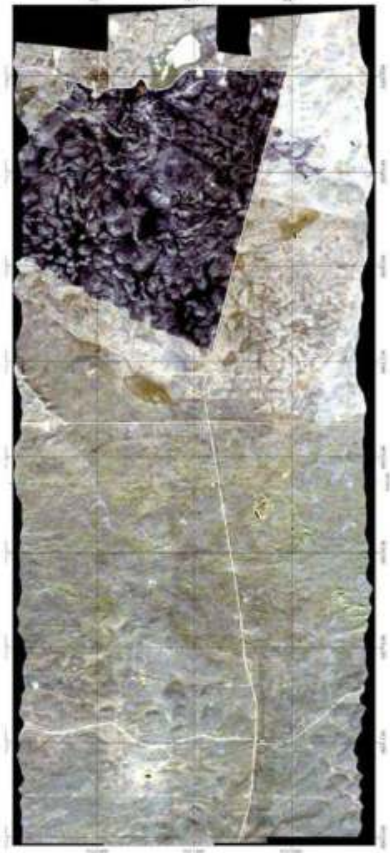

(a)

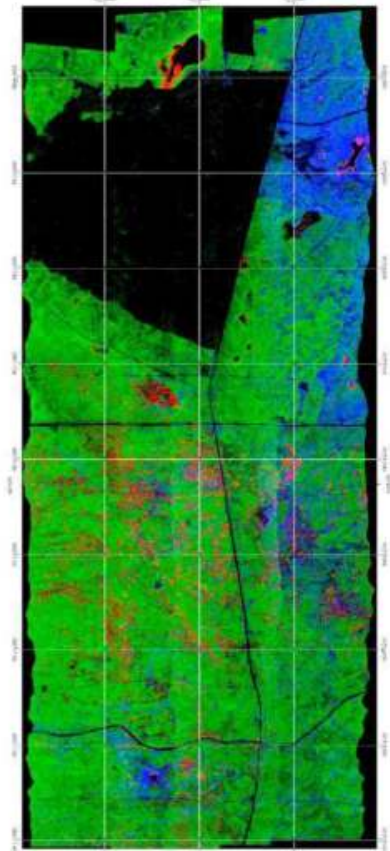

(b)

Fig. 15. (a) RGB “true color" (red: 640nm, green: 550nm, blue: 460nm) AISA image. (b) RGB composite image of the most widely spread green vegetation endmember (Red) and two dominant dry vegetation endmembers (green, blue). (B. Rivard, U. of Alberta).

\begin{tabular}{|l|c|c|}
\hline \multicolumn{1}{|c|}{ Class } & Train & Test \\
\hline dirt road & 15 & 15 \\
\hline paved road & 52 & 50 \\
\hline conifer forest & 140 & 62 \\
\hline deciduous forest & 263 & 113 \\
\hline grass & 170 & 80 \\
\hline clearcut area & 143 & 58 \\
\hline water & 106 & 39 \\
\hline
\end{tabular}

(a)

\begin{tabular}{|l|l|l|}
\hline \multicolumn{1}{|c|}{ Class } & Train & Test \\
\hline water & 49 & 49 \\
\hline trees & 91 & 98 \\
\hline shrubs & 68 & 65 \\
\hline muskeg & 36 & 50 \\
\hline gravel & 40 & 35 \\
\hline grass & 33 & 37 \\
\hline
\end{tabular}

(b)

Table 3. Number of training and test pixels for each class: (a) classes for CFB Gagetown data (Probe-1, 15m GSD) and (b) classes for CFB Wainwright data, (AISA, 4m GSD).

During the comparison, it was found that the tested algorithms behaved differently as the number of bands used in the classification process increases. Some see classification accuracy increase, others prove unaffected by the number of bands while a third group see the accuracy decrease, albeit slightly.

An immediate advantage in using fewer bands is that processing times are shorter, which is very convenient when analyzing large files. It can also be useful to identify which 
algorithms are most consistent in accuracy as the number of bands is changed. This way, by using a classification algorithm with known consistency, the optimal band-set can be selected quickly after performing a few tests.

The major finding was that the Mercury algorithm consistently provides very high overall classification accuracy values as illustrated in Table 4 . It proves stable and offers the advantage of not requiring that the number of training pixels for each class be at least equal to the number of bands used plus one as is the case with the Maximum Likelihood and Mahalanobis Distance techniques. Mercury's accuracy increased with the number of bands and it offered the highest individual accuracy values in both datasets. Using Mercury on the principal components yielded lower accuracy than with the original dataset. With the Maximum Likelihood algorithm applied to the principal components, results were almost identical to those obtained with the original data. The following table illustrates the findings.

\begin{tabular}{|c|c|c|c|c|c|}
\hline Number of bands $\rightarrow$ & $\mathbf{4}$ & $\mathbf{7}$ & $\mathbf{2 0}$ & $\mathbf{5 0}$ & Average \\
\hline Mercury & $82.30 \%$ & $83.60 \%$ & $88.20 \%$ & $91.30 \%$ & $\mathbf{8 6 . 4} \%$ \\
\hline Support Vector Machine & $84.40 \%$ & $83.10 \%$ & $84.40 \%$ & $85.60 \%$ & $\mathbf{8 4 . 4 \%}$ \\
\hline Mahalanobis Distance & $77.60 \%$ & $75.20 \%$ & $86.20 \%$ & $89.50 \%$ & $\mathbf{8 2 . 1 \%}$ \\
\hline Neural Network & $81.60 \%$ & $84.20 \%$ & $88.30 \%$ & $65.20 \%$ & $\mathbf{7 9 . 8} \%$ \\
\hline Maximum Likelihood & $87.60 \%$ & $73.00 \%$ & $77.40 \%$ & $75.20 \%$ & $\mathbf{7 8 . 3} \%$ \\
\hline Minimum Distance & $80.30 \%$ & $76.70 \%$ & $76.60 \%$ & $76.50 \%$ & $\mathbf{7 7 . 5} \%$ \\
\hline Parallelepiped & $75.60 \%$ & $74.00 \%$ & $77.40 \%$ & $77.00 \%$ & $\mathbf{7 6 . 0} \%$ \\
\hline Spectral Angle & $67.20 \%$ & $67.60 \%$ & $68.80 \%$ & $69.00 \%$ & $\mathbf{6 8 . 2} \%$ \\
\hline $\begin{array}{c}\text { Spectral Information } \\
\text { Divergence }\end{array}$ & $68.70 \%$ & $66.60 \%$ & $68.40 \%$ & $67.60 \%$ & $\mathbf{6 7 . 8} \%$ \\
\hline Binary Encoding & $52.00 \%$ & $51.40 \%$ & $56.60 \%$ & $66.70 \%$ & $\mathbf{5 6 . 7 \%}$ \\
\hline
\end{tabular}

Table 4. Comparison of Mercury and ENVI supervised classification algorithms accuracy. Green is for the algorithm that ranked $1^{\text {st }}$ in classification accuracy and yellow is the algorithm that ranked second.

The study also highlighted the fact that class accuracy varies greatly with the choice of bands in most algorithms. Figures ranging from $0 \%$ to $100 \%$ accuracy were observed in some algorithms but Mercury came out with very consistent global figures.

In summary, Mercury compares very favourably with ITT's offering for global and class accuracy and for all algorithms, one would be well advised to run a few tests as to the number and choice of bands to ensure optimal feature accuracy.

\subsection{Chemical effects on vegetation}

\subsubsection{Plants as chemical detectors}

The Canadian Centre for Mine Action Technologies initiated a study in 2003 to investigate the possibility of exploiting advances in genetic engineering and plant biotechnology to design a process by which plants, local to a region of interest, could be genetically modified 
(GM) to be sensitive to the compounds known to permeate the soil around emplaced landmines. In this case it was envisioned that the plant's genes would also be designed to include a reporting mechanism, signalling the presence of these compounds through a change in the plant's structure, appearance or some other physical characteristic. The Deyholos group at the University of Alberta was funded to conduct the initial study (Deyholos et al, 2006).

At the same time, the United States' Defense Advanced Research Projects Agency (DARPA) inititated the Biological Input Output Systems (BIOS) program. The BIOS program's objective was to produce basic biochemical modules for future use in plant or microbialbased detectors of chemical and biological compounds of strategic interest. Collaboration between the two projects advanced efforts in developing a human-readable biological signalling event (Deyholos et al, 2007; Antunes et al, 2006)

The DARPA-funded team at Colorado State University went on to develop the first generation plant-based sensor capable of detecting 2,4,6-TNT in the low ppt (parts per trillion) range. The Canadian effort made significant progress in the development of a rootto-shoot transducer system and an effective visual reporter system (Deyholos, 2009).

This effort clearly demonstrated that plants' natural responses to chemicals in their environment could be harnessed, exploited and enhanced to provide an in situ chemical detection capability of remarkable sensitivity. This observation, amongst others, led to a study to investigate whether it might be possible to detect, through optical means, the naturally occurring effects of exposure to various chemical agents on vegetation, by which in situ vegetation may provide a highly sensitive stand-off detection capability to chemical exposures occurring at ground level. These agents cause stress and damage to surrounding vegetation the extent of which is dependent on dosage and time of exposure.

\subsubsection{Passive detection}

It is well recognized that reflective hyperspectral imagery $(400-2500 \mathrm{~nm})$ is well suited to analyze vegetation. Under the Canadian Space Agency HERO program, a feasibility study was conducted (Peddle et al, 2008) to determine whether a space-based system such as HERO can be used to detect toxic industrial chemicals indirectly by detecting the stress that these chemical cause on vegetation. Recognizing that this could have a potential military application, we pursued this project under HYMEX by conducting a laboratory evaluation of the stresses caused by various chemicals.

The aim of this investigation was to provide information that would help quantify the potential of reflective hyperspectral imagery for chemical and biological surveillance, reconnaissance involving plants exposed to Toxic Industrial Chemicals and Materials (known as TICs and TIMs, such as Ammonia, Sulphur Dioxide, Chlorine, Hydrogen Sulphide, Hydrogen Cyanide, Cyanides, Phosgene).

The two objectives of this study were to determine if: 1) vegetation subjected to TICs could be distinguished from background vegetation during varying growth stages (new growth to senescence) and environmental stresses; and, 2) different TICs could be distinguished based on the vegetation spectral response. This work was conducted by teams at the University of Alberta (Rivard et al, 2008). 
This research team examined the spectral response of individual leaves of three common Canadian plant species (poplar (Populus deltoides, Populus trichocarpa), wheat (Triticum aestivum), canola (Brassica napus)), which were subjected to fumigation with gaseous phase toxic industrial chemicals and chemicals precursor to chemical warfare agents (e.g. ammonia and sulphur dioxide) (TICs). Treatments were designed to allow quantification of the variation in spectra that might be expected due to environmental, developmental, and stochastic effects on the physiological state of individual plants within each species.

The test plants were grown in controlled environment chambers at the University of Alberta, using standardized conditions. Each spectral measurement collected with the ASD® FR spectrometer, as shown in Figure 16, consisted of an average of 10 scans. Multiple scans were taken per leaf location to reduce the effects of noise. For each leaf, three different locations were measured located approximately halfway between the main leaf vein and the leaf edge, precluding overlap of areas measured. The measurements from each leaf were then averaged accounting for spectral variability across the leaf. For smaller leaves (e.g. new growth) only one or two measurements were possible.

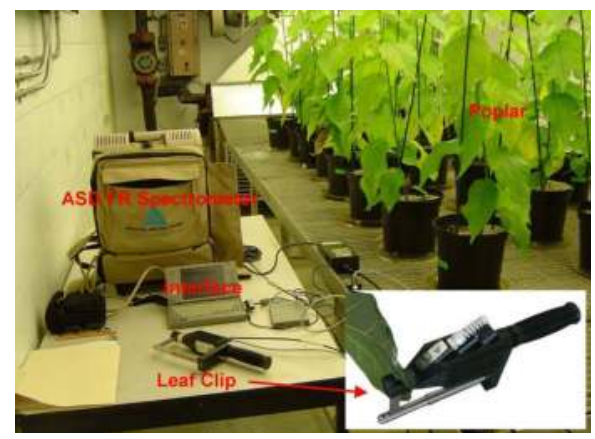

Fig. 16. Basic set-up for spectral measurements. Inset is an image of the ASD® Leaf Clip, the field spectrometer used to collect plant data.

The study was broken into two phases: 1) to capture the spectral variability of the various leaf growth stages (new to senescing leaves) observed in each of the three plant types; and 2) subjecting the plants to environmental stresses (e.g. drought) and the following five industrially relevant gaseous phase TICs: ammonia $\left(\mathrm{NH}_{3}\right)$, sulphur dioxide $\left(\mathrm{SO}_{2}\right)$, hydrogen sulphide $\left(\mathrm{H}_{2} \mathrm{~S}\right)$, chlorine $\left(\mathrm{Cl}_{2}\right)$, and hydrogen cyanide $(\mathrm{HCN})$. The experimental data were analyzed to determine if the various treatments resulted in specific leaf spectral features related to TICs. Figure 17 illustrates typical effects of the chemicals on plants and Figure 18 depicts representative spectra collected, in this case for canola exposed to $\mathrm{Cl}_{2}$ and $\mathrm{SO}_{2}$. Here one can see key absorption features observed in endmember spectra, which were exploited in subsequent analysis.

Observations showed that both environmental stress and TIC treatments induce similar spectral features inherent to plants, which can be related primarily to chlorophyll and water loss. These include pigments in the visible and cellulose, lignin, lipids, starches, and sugars in the short wave infrared. Although no specific spectral features could be tied to individual TICs, an analysis of the data using vegetation indices, which focus on key spectral bands associated with chlorophyll, pigments and water content, showed that the TICs and 

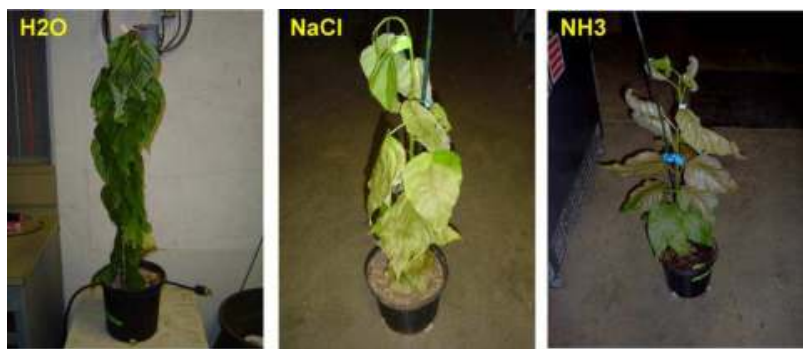

Fig. 17. Examples of environmental $\left(\mathrm{H}_{2} \mathrm{O}, \mathrm{NaCl}\right)$ and chemicals $\left(\mathrm{NH}_{3}\right)$ stresses on plants.
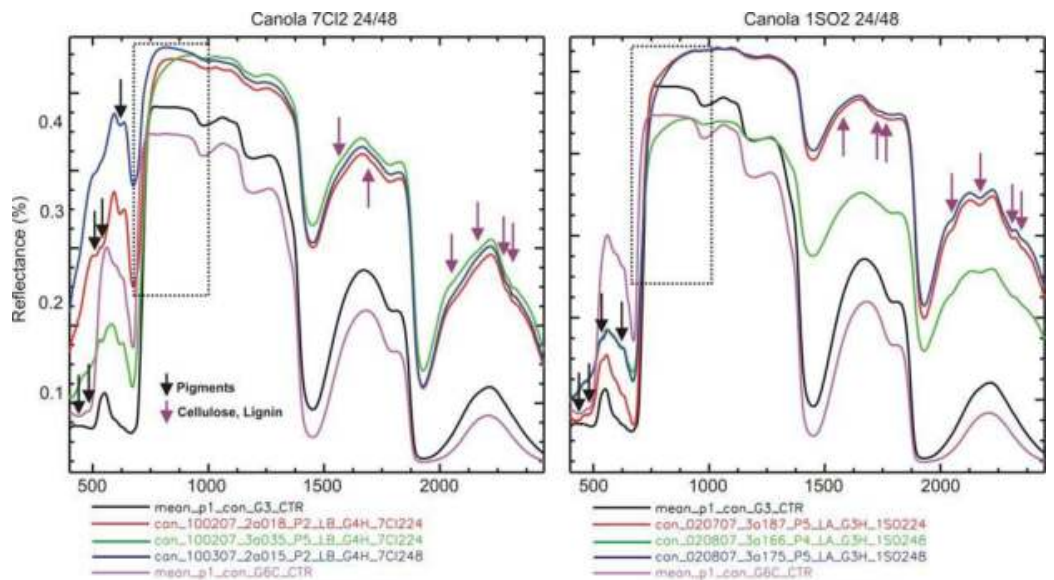

Fig. 18. Representative spectra for canola experiments using $\mathrm{Cl}_{2}$ and $\mathrm{SO}_{2}$. Mean spectra of control G1 (black line, mature healthy) and G4C (pink line, high senescence) are included for reference. Arrows denote key absorption features observed in endmember spectra compared with G1. Black dotted box denotes smoothing of red edge. Chemical exposure differences is apparent.

environmental stresses result in diagnostic light reflectance data trends from healthy mature to highly stressed leaves.

Comparison of relevant vegetation indices, such as that depicted in Figure 19, showed that specific combinations could be used to distinguish $\mathrm{NH}_{3}, \mathrm{SO}_{2}, \mathrm{Cl}_{2}$ consistently across all three species (Rogge et al, 2008). The trends result from the variable leaf response within plants, between plants and between species and it is expected much of the variability observed within species would be preserved or even enhanced in nature. As such it is encouraging for the possible detection of TIC effects on natural vegetation using airborne/spaceborne imagery.

As the detection methodology was developed from leaf-level observations, it is important to note that field trials remain to be conducted in order to test if the findings of this study can be extended to the detection of TICs in the natural environment. The principal unknown is the effect of varying vegetation canopy structural parameters (e.g. canopy gaps, leaf area) and background properties (litter and soil reflectance) on the specific data trends that were identified. 

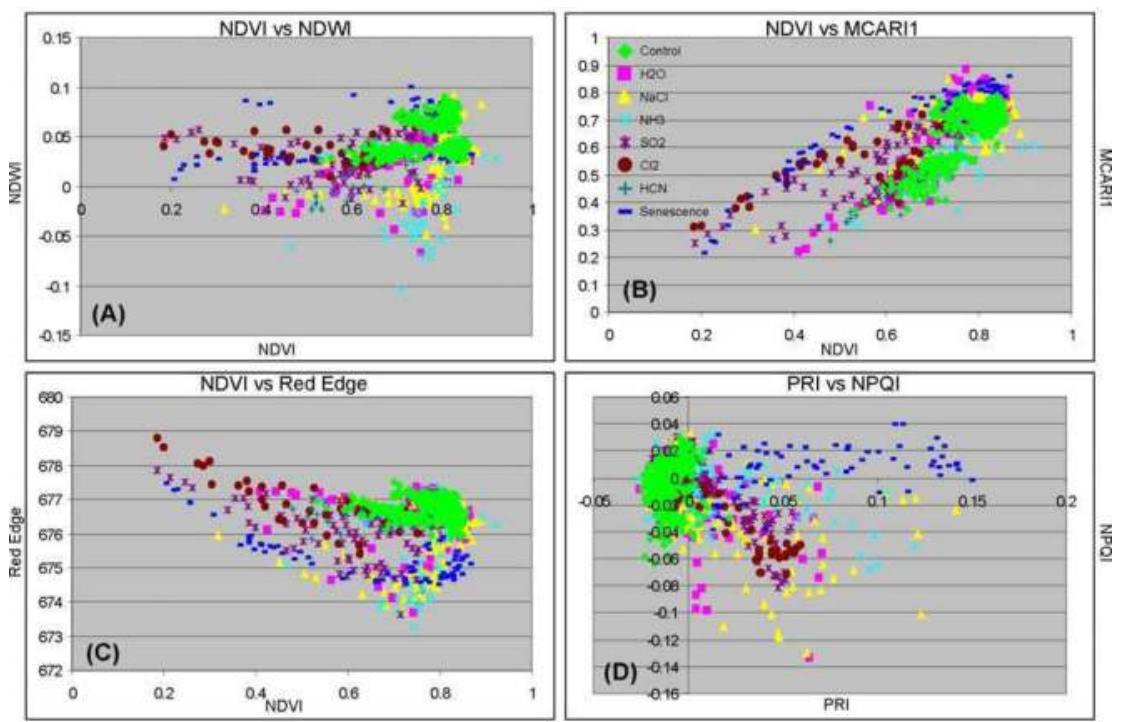

Fig. 19. A selection of vegetation indices across all species for treatments with $\mathrm{NaCl}, \mathrm{NH}_{3}$, $\mathrm{SO}_{2}, \mathrm{Cl}_{2}, \mathrm{HCN}$, and, dehydration $\left(\mathrm{H}_{2} \mathrm{O}\right)$, senescence and controls plants. The existence of species-specific responses of vegetation to TICs presents both a challenge and an opportunity for regional remote sensing.

While the exact physiological response to each stressor remains to be understood, the existence of species-specific responses of vegetation to TICs presents both a challenge and an opportunity for regional remote sensing.

\section{Marine algorithms}

The HYMEX project studied several potential marine applications in collaboration with Borstad Associates and the Dept. of Fisheries and Ocean (Institut Maurice Lamontagne and Bedford Institute of Oceanography). We conducted airborne hyperspectral surveys on East and West coasts of Canada to evaluate algorithms for near-shore bathymetry, beach trafficability, near-shore bottom type mapping as well as retrieval of chlorophyll and suspended matter concentrations as indicator of water clarity. More details are provided in (Ardouin, 2007). Through this work it was realized that most of these algorithms can be applied to multispectral imagery and that their experimental validation is difficult. The later is particularly true for products that vary with time (or current) and thus would require many measurement stations (for validation) that would need to operate coincidentally with the airborne survey and be distributed over the area of the survey.

More recently, we tasked OEA Technologies to provide an operational assessment of HYMEX marine algorithms. In this assessment, a distinction was made between dynamic (e.g. water color) and static (e.g. bathymetry) products. It was pointed out that the Canadian Forces needs for off-shore dynamic products (e.g. water colour) is already fulfilled by marine multispectral sensors (MERIS, MODIS) with pixel size $>250 \mathrm{~m}$ (Williams, 2009). There might however be a niche for hyperspectral sensors (airborne and spaceborne) which 
typically have better spatial resolution (e.g. from submeter to tens of meter) for near-shore static and dynamic products. The better spatial resolution and increased number of bands of hyperspectral sensors might provide an ability to handle the more complex near-shore environment. Potential static products to consider include target detection and near-shore bottom characterization in support of mine countermeasures and battlespace mapping and possibly submarine operations. To this we can also add near-shore bathymetry in support of route survey, battlespace mapping, anti-submarine warfare and submarine operations. While not requiring hyperspectral sensing, HSI could keep playing a role (e.g. selection of optimal bands) in the development of new dynamic products for both near-shore and offshore applications. Overall, this assessment point to possible follow-up for marine applications development with hyperspectral sensors.

\section{Conclusion}

In this chapter, we discussed a wide variety of military applications resulting from the exploitation of reflective hyperspectral imagery. These applications were demonstrated in the DRDC HYMEX project, allowing DRDC and the Canadian Forces stakeholders to get more familiar with the military utility of hyperspectral imagery. While some of these applications such as target detection are relatively mature and are near to operational deployment, others still require further development but are representative of the unique capability of hyperspectral remote sensing. The many datasets that were acquired and the algorithms and exploitation tools that were developed in the project are being used to continue the development of hyperspectral technology at DRDC. One avenue that is being pursued is the development of an airborne hyperspectral real-time target detection demonstration system. We are also looking at opportunities to further develop the land mapping and marine applications areas as well as potential space-based demonstration with international partners.

\section{References}

Antunes, M.S.; Ha, S.B.; Tewari-Singh, N.; Morey, K.J.; Trofka, A.M.; Kugrens, P.; Deyholos, M. \& Medford J.I. (2006) A synthetic de-greening gene circuit provides a reporting system that is remotely detectable and has a re-set capacity, Plant Biotechnology J., Vol. 4, No. 6, (November 2006), pp. 605-622

Ardouin, J.-P.; Lévesque, J. \& Rea, T.A. (2007) A Demonstration of Hyperspectral Image Exploitation for Military Applications, Proc. of the 10th International Conference on Information Fusion (FUSION 2007), Quebec, Canada, (9-12 July 2007), pp. 1-8., ISBN 978-0-662-45804-3

Beeftink, H.H. (1951) Some observations on tamarack or eastern larch. Forestry Chronicle, Vol. 27, No. 1, (1951), pp. 38-39

Bernstein, L.S.; Adler-Goldstein, S.M.; Sundberg, R.L., Levine, R.Y.; Perkins, T.C.; Berk, A.; Ratkowski, A.J.; Felde, G. \& Hoke, M.L. (2005) A new method for atmospheric correction and aerosol optical property retrieval for VIS-SWIR multi- and hyperspectral imaging sensors: QUAC (QUick Atmospheric Correction), IEEE International Geoscience and Remote Sensing Symposium, (25-27 July 2005), pp. 35493552, ISBN 0-7803-9050-4 
Buckingham, R.; Staenz, K. \& Hollinger (2002) A., Review of Canadian Airborne and Space Activities in Hyperspcetral Remote Sensing, Canadian Aeronautics and Space Journal, Vol. 48, No. 1, (2002), pp. 115-121

Buckingham, R. \& Staenz, K. (2008) Review of current and planned civilian space hyperspectral sensors for EO, Can. J. Remote Sensing, Vol. 34, Suppl. 1, (2008), pp. S187-S197

Cooley T.; Davis, M. \& Straight, S. (2006) ARTEMIS-Advanced Tactically-Effective Military Imaging Spectrometer: Tactical Satellite 3 for Responsive Space Missions, International Symposium on Spectral Sensing Research, Bar Harbor, MN, (May 2006)

Cutter, M.A.; Johns, L.S.; Lobb, D.R.; Williams, T.L. \& Settle, J.J. (2003) Flight Experience of the Compact High Resolution Imaging Spectrometer (CHRIS), Proc. of SPIE Imaging Spectrometry IX. Vol. 5159, (2003) pp. 392-405

Davenport, M. \& Ressl, W. (1999) Shadow Removal in Hyperspectral Imagery, International Symposium on Spectral Sensing Research (ISSSR 99), Las Vegas (November 1999)

Deyholos, M.; Faust, A.A.; Miao, M.; Montoya, R. \& Donahue, D.A. (2006) Feasibility of landmine detection using transgenic plants, in Detection and Remediation Technologies for Mines and Minelike Targets XI, J. Thomas Broach, Russell S. Harmon, John H. Holloway, Jr, eds., Proc. SPIE, Vol. 6217, (May 2006), pp. 700-711

Deyholos, M.K.; Rogge, D.; Rivard, B. \& Faust, AA. (2007) Plants as sensors for toxic industrial chemicals and munitions: A feasibility analysis, In Vitro Cellular $\mathcal{E}$ Developmental Biology-Animal, Vol. 43, pp. S7-S7.

Deyholos, M. (2009) Demonstration of Plant-based Explosives Detection, Contract Report Defence R\&D Canada - Suffield, DRDC Suffield CR-2010-010 (2009).

Pearlman, J.S.; Barry, P.S; Segal, C.C.; Shepanski, J.; Beiso \& D. \& Carman, S.L. (2003) Hyperion, a Space-Based Imaging Spectrometer, IEEE Trans. on Geoscience and Remote Sensing, Vol. 41, No. 6, (June 2003), pp. 1160- 1173, ISSN 0196-2892

Peddle, D.R. \& Ferguson, D.T. (2002) Optimization of Multisource Data Analysis using Evidential Reasoning for GIS Data Classification, Computers \& Geosciences, Vol. 28, No 1, (2002), pp. 45-52

Peddle, D.R.; Franklin, S.E.; Johnson, R.L.; Lavigne, M.B. \& Wulder, M.A. (2003) Structural Change Detection in a Disturbed Conifer Forest Using a Geometric Optical Reflectance Model in Multiple-Forward Mode. IEEE Trans. on Geoscience and Remote Sensing Vol. 41, No. 1, (Jan 2003), pp. 163-166, ISSN 0196-2892

Peddle, D.R. \& Smith, A.M. (2005) Spectral Mixture Analysis of Agricultural Crops: Endmember Validation and Biophysical Estimation in Potato Plots, International Journal of Remote Sensing, Vol. 26, No. 22, (2005), pp. 4959-4979

Peddle, D.R.; Boulton, R.B.; Pilger, N.; Bergeron, M. \& Hollinger, A. (2008) Hyperspectral detection of chemical vegetation stress: evaluation for the Canadian HERO satellite mission, Can. J. Remote Sensing, Vol. 34, Suppl. 1, (2008), pp. S198-S216

Reed, I. S. \& Yu, X. (1990) Adaptive multiple-band CFAR detection of an optical pattern with unknown spectral distribution, IEEE Trans. on Acoustics, Speech, and Signal Processing, Vol. 38, No. 10, (October 1990), pp. 1760-1770, ISSN 0096-3518

Rivard, B.; Deyholos, M. \& Rogge, D. (2008) Chemical Effects on Vegetation Detectable in optical bands 350-2500 nm, Contract Report Defence R\&D Canada - Suffield , DRDC Suffield CR-2008-234, (2008) 
Rogge, D.; Rivard, B.; Deyholos, M.; Lévesque, J. \& Faust, A. (2008) Toxic Industrial Chemical Effects on Poplar, Canola, and Wheat detectable over the 450-2500 nm Spectral Range, Intl. Geoscience E Remote Sensing Symposium (IGARSS 2008), Boston, MA, (July 2008)

Roy, V. (2010) Hybrid algorithm for hyperspectral target detection, Proc of SPIE Algorithms and Technologies for Multispectral, Hyperspectral, and Ultraspectral Imagery XVI, Vol. 7695, May 2010, pp. 1-10

Sentlinger, G.; Davenport M., \& Ardouin, J.-P. (2003) Automated Target Recognition in Hyperspectral Imagery using Subpixel Spatial Information, Proc. SPIE Aerosense Automatic Target Recognition XIII, Vol 5094, (April 2003)

Settle, J. (2002) On constrained energy minimization and the partial unmixing of multispectral images, IEEE Trans. on Geoscience and Remote Sensing, Vol. 40, No. 3, (March 2002), pp. 718-721, ISSN 0196-2892

Settle, J. (2004) On the Use of Remotely Sensed Data to Estimate Spatially Averaged Geophysical Variables, IEEE Trans. on Geoscience and Remote Sensing, Vol. 42, No. 3, (March 2004), pp. 620-631, ISSN 0196-2892

Smith, G. M. \& Milton, E.J. (1999) The use of the empirical line method to calibrate remotely sensed data to reflectance, International Journal of Remote Sensing, Vol. 20, (1999), pp. 2653-2662

Van Chestein, Y. (2011) Comparative evaluation of the Mercury classification algorithm: On the influence of the number of bands on classification accuracy using hyperspectral data, Defence R\&D Canada - Valcartier Technical Memorandun, TM 2010-385, (March 2011)

Webster, A.H.; Davenport, M.R. \& Ardouin, J.-P. (2006) 3D Deconvolution of Vibration Corrupted Hyperspectral Images, International Symposium on Spectral Sensing Research 2006, Bar Harbor, MA., (May 2006).

Williams, D.; Vachon, P.W; Wolfe, J.; Robson, M.; Renaud, W.; Perrie, W.; Osler, J.; Isenor, A.W.; Larouche, P.; Jones, C. (2009) Spaceborne Ocean Intelligence Network - SOIN fiscal year 08/09 year-end summary, Defence R\&D Canada - Ottawa External Client Report, DRDC Ottawa ECR 2009-139, (September 2009) 


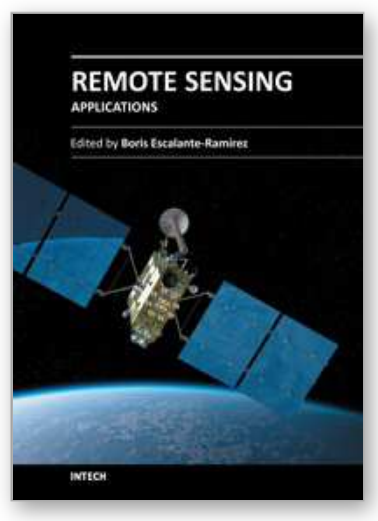

\author{
Remote Sensing - Applications \\ Edited by Dr. Boris Escalante
}

ISBN 978-953-51-0651-7

Hard cover, 516 pages

Publisher InTech

Published online 13, June, 2012

Published in print edition June, 2012

Nowadays it is hard to find areas of human activity and development that have not profited from or contributed to remote sensing. Natural, physical and social activities find in remote sensing a common ground for interaction and development. This book intends to show the reader how remote sensing impacts other areas of science, technology, and human activity, by displaying a selected number of high quality contributions dealing with different remote sensing applications.

\title{
How to reference
}

In order to correctly reference this scholarly work, feel free to copy and paste the following:

Jean-Pierre Ardouin, Josée Lévesque, Vincent Roy, Yves Van Chestein and Anthony Faust (2012). Demonstration of Hyperspectral Image Exploitation for Military Applications, Remote Sensing - Applications, Dr. Boris Escalante (Ed.), ISBN: 978-953-51-0651-7, InTech, Available from:

http://www.intechopen.com/books/remote-sensing-applications/demonstration-of-hyperspectral-imageexploitation-for-military-applications

\section{INTECH}

open science | open minds

\section{InTech Europe}

University Campus STeP Ri

Slavka Krautzeka 83/A

51000 Rijeka, Croatia

Phone: +385 (51) 770447

Fax: +385 (51) 686166

www.intechopen.com

\section{InTech China}

Unit 405, Office Block, Hotel Equatorial Shanghai

No.65, Yan An Road (West), Shanghai, 200040, China

中国上海市延安西路 65 号上海国际贵都大饭店办公楼 405 单元

Phone: +86-21-62489820

Fax: $+86-21-62489821$ 
(C) 2012 The Author(s). Licensee IntechOpen. This is an open access article distributed under the terms of the Creative Commons Attribution 3.0 License, which permits unrestricted use, distribution, and reproduction in any medium, provided the original work is properly cited. 